\title{
SONOGRAPHIC EVALUATION OF ESTIMATED FETAL WEIGHT BY DIFFERENT METHOD AT TERM AND POST TERM
}

\author{
Ammara Gulzar (Corresponding author)
}

Doctor of Medical Imaging Technology, Department of Allied Health Sciences, Superior College Lahore, University Campus, 17-KM Raiwaind Road, Kot Arain, Lahore, Pakistan

Mob:+92306-4122147 E-mail: ammaragulzar0000@gmail.com

\section{Maila Khan}

Doctor of Medical Imaging Technology, Department of Allied Health Sciences, Superior College Lahore, University Campus, 17-KM Raiwaind Road, Kot Arain, Lahore, Pakistan

Mob: 0302-3549073 E-mail: mailakhan38@gmail.com

\section{Waqas Jabbar}

Doctor of Medical Imaging Technology, Department of Allied Health Sciences, Superior College Lahore, University Campus, 17-KM Raiwaind Road, Kot Arain, Lahore, Pakistan

Mob: 0303-3754708 E-mail: jutt68999@gmail.com

\section{Wasim Sajid}

Masters in Diagnostic Ultrasound, Lecturer, Department of Allied Health Sciences, Superior College Lahore, University Campus, 17-KM Raiwaind Road, Kot Arain, Lahore, Pakistan

Mob: 0332-7639070 E-mail: wasim1128@gmail.com

\section{Tuseef Ahmed}

Masters in Medical Imaging Technology, Lecturer, Faculty of Allied Health Sciences, The University of Lahore, 1-KM Defence Road, near Bhuptian Chowk, Lahore, Pakistan

Mob: 0331-7778708 E-mail: tuseef.ahmed@mlt.uol.edu.pk

Rana Muhammad Athar Azeem Shams

Masters in Medical Imaging Technology, Lecturer, Department of Allied Health Sciences, Superior College Lahore, University Campus, 17-KM Raiwaind Road, Kot Arain, Lahore, Pakistan

Mob: 0334-6996693 E-mail: atharshams44@gmail.com

Rana Muhammad Bakhtawar Khan Sajawal

Masters in Mathematics, Lecturer, Department of Allied Health Sciences, Superior College Lahore, University Campus, 17-KM Raiwaind Road, Kot Arain, Lahore, Pakistan

Mob: 0304-2050204 E-mail: bksajawal77@gmail.com

\section{Amna Babar}

Masters in Diagnostic Ultrasound, Lecturer, Department of Allied Health Sciences, Superior College Lahore, University Campus, 17-KM Raiwaind Road, Kot Arain, Lahore, Pakistan

Mob: 0315-4172465 E-mail: amnababar18@gmail.com 
Sybil Rose

Masters in Diagnostic Ultrasound, Lecturer, Department of Allied Health Sciences, Superior College Lahore, University Campus, 17-KM Raiwaind Road, Kot Arain, Lahore, Pakistan

Mob: 0304-7757301 E-mail: sybilgill36@gmail.com

Hafiz Muhammad Rizwan

Masters in Medical Imaging Technology, Lecturer, Department of Allied Health Sciences, Superior College Lahore, University Campus, 17-KM Raiwaind Road, Kot Arain, Lahore, Pakistan

Mob: 0343-5135072 E-mail: dr.rzwaan@gmail.com

\begin{abstract}
Objective: To determine fetal weight estimation by different method on ultrasound at term \& to determine actual baby weight after birth

Methodology: The research is conducted in Meer Children and Family Clinic Tajpura Lahore. 121 women participate in this study over a 4 month period from January 2021 to April 2021. Systematic random sampling was used to make the selection. The scanner has Hadlock, Shepard, shibozuka and warsof formula.

Results: Out of 70 pregnant women in which 36 (51.5\%) nulliparous women and 34(48.5\%) multiparous women. A total of $45(64.3 \%)$ by vaginal delivery while $25(35.7 \%)$ deliver by $\mathrm{C}-$ Section. The minimum maternal age for nulliparous women is 21 years and maximum maternal age for multiparous is 39 years. The minimum Actual birth weight i.e. 2.40 correlate with estimated fetal weight. The maximum Actual birth weight i.e. 4.00 correlate with estimated fetal weight. The mean Actual birth weight is significantly increase with increase in both parity and maternal age at delivery

Conclusion: For most pregnant women, estimated fetal weight based on multiple fetal parameters provides reliable and clinically useful information. Despite the fact that there is still an acceptable difference between the actual birth weight and the sonographically EFW.
\end{abstract}

Keywords: Fetal Macrosomia, Term Pregnancy, Hadlocks Formula , Actual birth weight

DOI: $10.7176 / \mathrm{JHMN} / 91-11$

Publication date:July $31^{\text {st }} 2021$

\title{
1. Introduction
}

In low weight new born the death rate is forty times as compared to new born with normal weight. Annually $15.5 \%$ new born with less weight over 20 million infant, this number is $7 \%$ in advanced countries, $16.5 \%$ in less developed countries and $18.6 \%$ in under developed countries ${ }^{(1)}$. On the other hand, in developing countries the prevalence of macrosomia is between $5 \%$ to $20 \%$ but in past decades the ratio of macrosomia increase is between $15 \%$ to $20 \%{ }^{(2)}$.Fetus is that the unborn offspring that develop from embryo. The period that is starting from ninth week after fertilization to till birth is known as fetal period. The length of fetus is about $50 \mathrm{~mm}$ long and weight about 8 grams at the initial stage. During fetal period head growth is slow as compared to rest of body. The growth rate of body is very fast during fetal period ${ }^{(3)}$. The estimated date of labor at pregnancy is 280 days that is calculated from the LMP. According to some studies, the average pregnancy lasts 283 days. If the pregnancy is about 284 day it is considered as post term and reliable dating is prerequisite for best management of pregnancy past term ${ }^{(4)}$.

The average birth weight of new born is $3000 \mathrm{~g}$ to $3500 \mathrm{~g}$. Low birth weight is defined as $1501-2500 \mathrm{~g}$, very low birth weight is defined as $1001-1500 \mathrm{~g}$, and extremely low birth weight is defined as $500-1000 \mathrm{~g}$, which is referred to as macrosomia. If the birth weight is more than $4000 \mathrm{~g}$ it is considered as macrosomia ${ }^{(5)}$. During labor both increased fetal weight and low fetal weight are related to the high risk of infant complication ${ }^{(6)}$. LBW are at a higher danger if death and sickness no longer after birth and non-transmittable infection in the existence course. The main causes of LBW are preterm delivery and intrauterine growth retardation. The complication related to LBW are cognitive deficit, motor delays and other psychological problem. The influence factor of preterm birth are include fetal infection, Trauma, IUGR, Extrauterine infection and illness that bringing about growth retardation which at last outcome in $\mathrm{LBW}^{(7)}$. The mother related risk factor that may lead to low birth weight are poor nutrition, hypertension, insufficient prenatal care, Drug addiction, multiple pregnancies, young ages, heart disease and previous LBW infant ${ }^{(8)}$ Macrosomia is an obstetric condition that is related with other possibly dangerous complication to both fetus and mother. The maternal cause of fetal macrosomia is including obesity, maternal diabetes, previous large for gestational age, multiparity and postdate pregnancy. The fetal related reason 
of fetal macrosomia are fetal gender and congenital disorder such as weiderman syndrome ${ }^{(9)}$. Maternal complication related to fetal macrosomia are bone injuries, cesarean delivery, prolonged labor, infection, postpartum hemorrhage, labor augmentation with oxytocin and anesthetic accidents. Fetal complication associated with fetal macrosomia include brachial plexus injury, prenatal asphyxia, shoulder dystocia, hypoglycemia and skeletal injuries. The risk factor for macrosomia is fasting blood glucose, preeclampsia and gestational diabetes ${ }^{(10)}$. Some factors influence birth weight that are paternal height, gestation age at deliver or fetal sex , maternal weight, pregnancy weight gain, hypertension, uncontrolled diabetes and preeclampsia .The obesity and diabetes are maternal factor that cause abnormal fetal growth and lead to increase birth weight. During pregnancy the acquired complication such as preeclampsia can lead to low birth weight (11). Fetal weight assessment is an essential and global part of antenatal care, not just for delivery management and labor but frequently during the management of high risk pregnancies and growth monitoring. For newborn survival, $\mathrm{BW}$ of an infant is single most salient determinant ${ }^{(12)}$. In the long run, EFW is an important component in determining the delivery style and, as a result, the timing of labour induction. ${ }^{(13)}$ It is necessary to obtain exact assessment of prenatal fetal weight in utero to help the doctor determine whether or not to deliver the fetus as well as on fixing the deliver mode. ${ }^{(14)}$. In early day's fetal weight is observed manually by obstetrician by using Leopold's Maneuvers, Johnson's method, and Insler they measure abdominal girth and fundal height and use the clinical maternal measures to compute the fetal weight ${ }^{(15)}$

\subsection{Materials and Methods}

An analytical cross-sectional study was performed. The study was conducted in Meer Children and Family Clinic Tajpora Lahore. The data was collected in 4 months. Total 70 patients were included in our study. The inclusion criteria of our study were all pregnant women with $3^{\text {rd }}$ trimester. Patients with diabetic and hypertension, anomalous and abnormal babies were excluded. Patient was sent to radiology department for ultrasound. Ultrasound was contacted by resident sonologist with at least two years experiences. The ultrasound machine formula for estimating fetal weight was that devised by Hadlock on the basis of bi parietal diameter (BPD), head circumference, abdominal circumference, and femoral length. Within 30 minutes of delivery, the babies' birth weights were measured using a standard analogue scale. All data obtained during the study period were entered into a data form specifically designed for the study. The technique was demonstrated to a patient before she was positioned for scanning. For obstetric sonography a female nurse served as a chaperon during study period. Ask the patient to lie in the supine position with the head of the bed raised to 15 degrees. Exposé the abdomen from the xiphisternum to the pubic symphysis.After that, a liberal application of ultrasonic gel was added to the ex.Cover above and below where appropriate. The fetus was treated as an entity during the study, with thorough examinations of all organs and structures. They were fully screened (head, abdomen, limbs, heartbeats, orientation, presentation, position, amount of liquor, placenta position and maturity). Actual birth weight parity, maternal age, Hadlock, Shepard, shinzoka, Warsof, descriptive statistics were calculated ; for actual birth weight, Hadlock, Shepard, Shinzoka, Warsof, were evaluated by crosstab formula and frequency . PSNR test was applied for data analysis Correlation coefficient analysis was used to determine the relationship between Estimated Fetal Weight and Actual Birth Weight. Furthermore, bar chart, pia chart was used to evaluate equality and difference between estimated fetal weight and actual birth weight graphically. SPSS Computer software, version 25 was used to analysis the data. The rules and regulations set by the ethical committee of The Superior College were followed while conducting the research and the rights of the research participants were respected. Written informed consent form attached was taken from all the participants.

\section{Results}

Out of 70 pregnant women in which $36(51.5 \%)$ nulliparous women and 34(48.5\%) multiparous women. A total of $45(64.3 \%)$ by vaginal delivery while $25(35.7 \%)$ deliver by $\mathrm{C}-$ Section. The minimum maternal age for nulliparous women is 21 years and maximum maternal age for multiparous is 39 years. The minimum Actual birth weight i.e. 2.40 correlate with estimated fetal weight. The maximum Actual birth weight i.e. 4.00 correlate with estimated fetal weight. The mean Actual birth weight is significantly increase with increase in both parity and maternal age at delivery.

\section{Discussion}

A research conducted in Nigeria in 2015 by Eze CU, et al with the aim of comparing sonographically estimated fetal weight to real birth weight. They conveniently included 282 pregnant women, but we included 70 women by systematic random sampling. They found that the average approximate and real fetal weights at term were $337840 \mathrm{~g}$ and $339360 \mathrm{~g}$, respectively. They found 14.5 percent macrosomic and 15.2 percent macrosomic fetuses, 
but we omitted both classes to ensure that the weight estimation mode was correctly determined. They came to the conclusion that fetal weight calculated by ultrasound using the Hadlock-3 weight estimation model would positively correlate with actual birth weight. In our study Out of 70 pregnant women in which $36(51.5 \%)$ nulliparous women and 34(48.5\%) multiparous women. The minimum maternal age for nulliparous women is 21 years and maximum maternal age for multiparous is 39 years. The objective of our study to determine the accuracy of sonographically estimated fetal weight with actual birth weight ${ }^{(6)}$.

In obstetrics, accurate fetal weight measurement is important. Although fetal weight cannot be measured directly, different anatomical characteristics of the fetus and the mother can be used to estimate fetal weight. As in this research, ultrasound methods are among the most widely used methods. The combination of macrosomia and intrauterine growth inhibition raises the risk of neonatal disease, mortality and long-term neurological and developmental disabilities are also possible ${ }^{(1)}$.

It is however, less than the analysis conducted in United Kingdom where the average birth weight was 3,568 $496 \mathrm{~g}$ Regional factors (pandemics like malaria, which cause fetal anaemia linked to low birth weight), materna 1 factors (hypertension, paternal weight gain, maternal height, maturity level), and social factors (education, finan cial problems) can all influence birth weight ${ }^{(2)}$.

Furthermore, the formulas for estimating fetal weight are statistically important. In this analysis, there is no variation among actual birth weight and estimated fetal weight using Hadlock, which is comparable to a previous study in Bangladesh, where the average EFW was 2753.4 (716.4; interval, 1200-4184) g, which was almost identical to the actual mean body weight using the Hadlock et al process. The weights of the babies ranged from 1200 to 4500 grammes at birth. The calculated birth weights were $65 \mathrm{~g}$ lower than the normal birth weight. The average absolute difference between EFW and BW was 64.5 (218.5) g (95\% CI: $116.2 \mathrm{G}$ To $12.7 \mathrm{~g}$ ), and the mean relative difference or average error as a percentage of fetal weight estimate [100 (EFW-BW)/BW] was 1.4 percent 7.6 percent. In contrast to a study conducted in Germany, where the disparity between sonographic $\mathrm{EFW}$ using the $\mathrm{HC} / \mathrm{FL} / \mathrm{AC}$ and actual $\mathrm{BW}$ was greater, a strong correlation was observed between sonographic $\mathrm{EFW}$ using the $\mathrm{HC} / \mathrm{FL} / \mathrm{AC}$ and actual $\mathrm{BW}(\mathrm{r}=0.961)$. In a previous study, pregnant women at term were compared to the accuracy of eight sonographic formulas for predicting fetal $\mathrm{BW}$ at term in a multiethnic population $^{(5)}$.

Dimassi K, et al. conducted a prospective study in 2015 with the same aim of determining the accuracy of sonographically calculated fetal weight. They accompanied 500 singleton pregnancies for this study. The weight of the fetus was calculated sonographically before birth and weighed afterward. When the two weights were compared, the median difference was discovered to be $200 \mathrm{~g}$. The linear logistic regression revealed a very strong relationship, with an R-value of 0.79 and a p-value of 0.01 level significance. It is also supported by the findings of our research. In 2015, Dimassi K, et al. conducted ultrasound on 299 pregnant women who were 37 weeks or more together with the aim of determining inter-observer variability. He came to the conclusion that residents in the delivery room could measure fetal weight as accurately as experienced sonographers ${ }^{(7)}$.

Numerous methods of fetal weight calculation have been tested since the invention of ultrasonography fetal measurements. Obese patients, the anterior position of the placenta, and low amniotic fluid levels are all variables that may affect the consistency and precision of a sonographic inspection. Our findings, on the other hand, did not accept these factors as drawbacks in determining fetal weight.

\section{Conclusion}

The birth weight of the baby is an important factor in fetal and neonatal morbidity. The correct calculation of estimated fetal weight before delivery is necessary and greatly control the clinical management and outcomes of pregnancy fetus delivery and survival of neonatal in case of growth retardation of fetus. For most pregnant women, estimated fetal weight based on multiple fetal parameters provides reliable and clinically useful information. Despite the fact that there is still an acceptable difference between the actual birth weight and the sonographically estimated fetal weight, In addition, sonography appears to be a reliable predictor of both low and high-weight fetuses. Our sonographic modified regression model for EFW had the smallest divergence from actual neonatal birth weight and can be used reliably in our population

\section{Conflict of Interest}

There is no conflict of interest in this research.

\section{References}

1.Iltaf G, Beenish S, and Muhammad I K. Incidence and associated risk factor for LBW babies born in shaikh khalifa Bin zayad Al-Nayan Hospital Muzaffarabad, Azad Jammu kashmir.Pakistan Journal of Medical 
Science.2017;33(3):626-630.

2.Abubakari A, Gisela k-W, and Albrecht J. Prevelance of abnormal birth weight and related factors in northen region- Ghana.BioMedical Center.2015;15:335.

3.Klossner N.J. introductory Maternity and pediatric nursing. Library of Congress,2019; 3(08): 101-103.United State of America.

4.Moore k L., Persauid T.V.N. The developing Human Clinicaly oriental Embryology.Library of Congress.2009; 1(08): 139-153.United State of America.

5. Mallouli M, Mohammad D, Allegbe I, Jihen S, chekib Z, Thouraya A, Ali M.Associated outcome of fetal macrosomia effect of maternal diabetes. National Library of Medicine.2017; 95(2): 120-125..

6.Eze CU, Livinus CA, Jerone N,UdoO, Olayinka O. Correlation of ultrasonographic estimated fetal weight with actual birth weight in tertiary Hospital Lagos. African Health Science.2015;15(4):1112-1122.

7.Anil K.C., Prem L B, and Sarswati S. Low birth weight and its associated risk factors: Health facility based case-centeral study.National Center for Biotechnology Information.2020;15(6) : eo234907.

8.Rizzo Nicala, Giuliana S, and Alessandra C. Obstetrical risk factors for estimated low birth weight. Italian Journal of Pediatrics.2015;41(1):35.

9.Nkwabong E, and Guilherme Roger N T.Risk factor for macrosomua.Journal of Obstetrical and Gyneacology of india. 2015;65(4): 226-229.

10.Mohammad Beigi A, Farhadi Far F, N soufi Z, Mohammad Salehi N, Rezaiee M, and Aghaei M. Fetal macrosomia: Risk factors, maternal and perinatal outcome.Annals of Medicine and Health Science Research.2013;3(4):546-550.

11.Engelbrechtsen L., Gybel-Brask D., Mahendran y., crusell M., Hansen T.H., Schaurr T.M., Hogdall E., Skibstel L., and Vestergaard H. Birth weight variants are associated with variable fetal IUG 20 week of gestation. Nature Scientific Reports.2018;08:8376.

12.Njoku c, Cajethen E, Patience O, Sylvestre A, Chinedu C, and John E. Determination of accuracy of fetal weight using ultrasound and clinical fetal weight estimation in calabar south, south Nigeres. Nigerion journal of clinical practice.2014; 17(3):270-275.

13.Lanowski J-S, Gabriele L, Cordula S, kristina D, Peter H, and Ismini S. Ultrasound versus clinical examination to estimate fetal weight at term.National Center for Biotechnology Information.2017;77(3): $276-283$. 14.Kishor P Chauhan, Uday J Patel, Bakul R Leuva . Comparative study of various methods of fetal weight estimation at term pregnancy.The Journal of Integrated Health Sciences.2013 June. 1(1):1-6 .

15.Shittu AS, Kuti O, Orji EO, Makinde NO, Ogunniyi SO, Ayoola OO, et al. Clinical versus sonographic estimation of foetal weight in southwest Nigeria.Journal of health, population, and nutrition.2007;25(1):14 .

Table no 1: Correlation of Parity, Maternal Age, Hadlock, Shepared, Shinzoka, Warsof and Actual Birth weight

\section{Statistics}

\begin{tabular}{|c|c|c|c|c|c|c|c|c|}
\hline & & Hadlock & $\begin{array}{l}\text { Actual birth } \\
\text { weight }\end{array}$ & Parity & Shepared & shinozuka & $\begin{array}{l}\text { Maternal } \\
\text { Age }\end{array}$ & Warsof \\
\hline \multirow[t]{2}{*}{$\mathrm{N}$} & Valid & 70 & 70 & 70 & 70 & 70 & 70 & 70 \\
\hline & Missing & 0 & 0 & 0 & 0 & 0 & 0 & 0 \\
\hline \multicolumn{2}{|c|}{ Minimum } & 2.70 & 2.40 & 1 & 2.73 & 2.72 & 21.00 & 2.59 \\
\hline \multicolumn{2}{|c|}{ Maximum } & 4.24 & 4.00 & 5 & 4.23 & 4.11 & 39.00 & 4.08 \\
\hline
\end{tabular}


Table No 2: Shows parity status The maximum Parity status was P1 which shows high percentage cases of pregnant women. In P5 case the percentage value of pregnant women was minimum.

\begin{tabular}{lll|l} 
& & & \\
& & Frequency & Percent \\
\hline Valid & P1 & 36 & 51.4 \\
\cline { 2 - 4 } & P2 & 12 & 17.1 \\
\hline P3 & 9 & 12.9 \\
\hline P4 & 7 & 10.0 \\
\hline P5 & 6 & 8.6 \\
\hline Total & 70 & 100.0 \\
\hline
\end{tabular}

Table No 3: Pi chart Shows parity status The maximum Parity status was P1 which shows high percentage cases of pregnant women. In P5 case the percentage value of pregnant women was minimum.
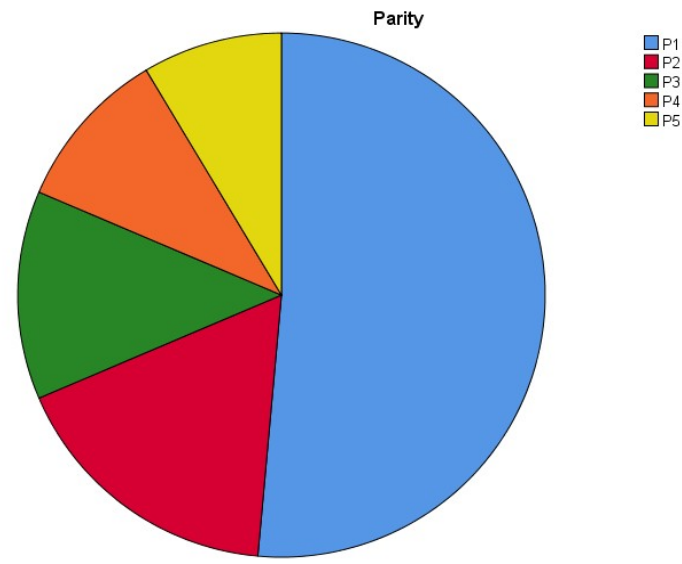

Table No 4: Shows materenal age calculation In 24 and 25 maternal age the maximum cases of $3^{\text {rd }}$ trimester women was calculated, The minimum cases calculated in 37 to 39 maternal age.

\begin{tabular}{lll|l} 
& & Frequency & Percent \\
\hline Valid & 21.00 & 2 & 2.9 \\
\cline { 2 - 4 } 22.00 & 7 & 10.0 \\
\hline 23.00 & 6 & 8.6 \\
\hline 24.00 & 8 & 11.4 \\
\hline 25.00 & 8 & 11.4 \\
\hline 26.00 & 3 & 4.3 \\
\hline 27.00 & 4 & 5.7 \\
\hline 28.00 & 4 & 5.7 \\
\hline 29.00 & 3 & 4.3 \\
\hline 30.00 & 5 & 7.1 \\
\hline 31.00 & 2 & 2.9 \\
\hline 32.00 & 4 & 5.7 \\
\hline
\end{tabular}




\begin{tabular}{|l|l|l|}
\hline 33.00 & 2 & 2.9 \\
\hline 34.00 & 3 & 4.3 \\
\hline 35.00 & 4 & 5.7 \\
\hline 36.00 & 2 & 2.9 \\
\hline 37.00 & 1 & 1.4 \\
\hline 38.00 & 1 & 1.4 \\
\hline 39.00 & 1 & 1.4 \\
\hline Total & 70 & 100.0 \\
\hline
\end{tabular}

Table No 5: Pi Chart Shows maternal age distribution In 24 and 25 maternal age the maximum cases of $3^{\text {rd }}$ trimester women was calculated, The minimum cases calculated in 37 to 39 maternal age.

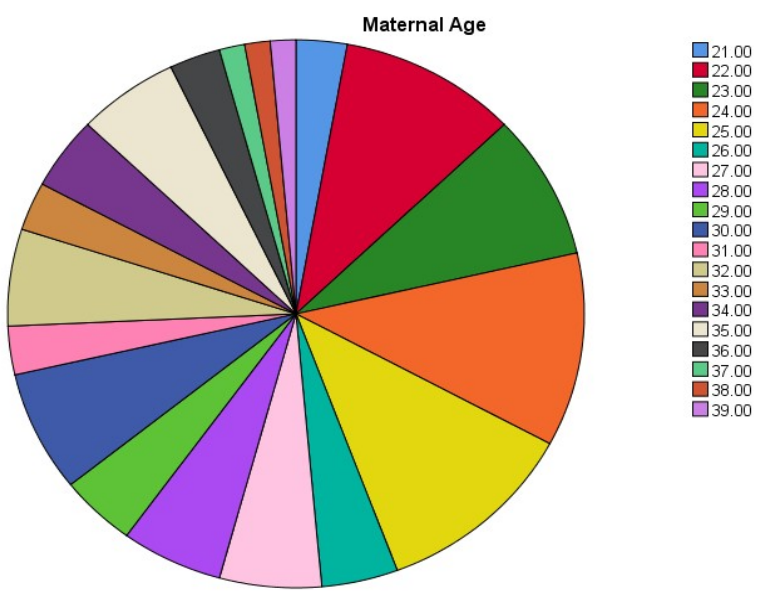

Table No 6: Shows measurements of actual birth weight the maximum Actual birth weight was 3.00 which shows similarity with sonographically estimated fetal weight.

\begin{tabular}{|c|c|c|c|}
\hline & & $\begin{array}{l}\text { Frequenc } \\
\mathrm{y}\end{array}$ & Percent \\
\hline \multirow[t]{15}{*}{ Valid } & 2.40 & 1 & 1.4 \\
\hline & 2.60 & 1 & 1.4 \\
\hline & 2.70 & 2 & 2.9 \\
\hline & 2.80 & 5 & 7.1 \\
\hline & 2.90 & 5 & 7.1 \\
\hline & 3.00 & 16 & 22.9 \\
\hline & 3.10 & 3 & 4.3 \\
\hline & 3.20 & 6 & 8.6 \\
\hline & 3.30 & 1 & 1.4 \\
\hline & 3.40 & 8 & 11.4 \\
\hline & 3.50 & 7 & 10.0 \\
\hline & 3.60 & 4 & 5.7 \\
\hline & 3.70 & 1 & 1.4 \\
\hline & 3.80 & 4 & 5.7 \\
\hline & 3.90 & 1 & 1.4 \\
\hline
\end{tabular}




\begin{tabular}{l|l|l}
\hline 4.00 & 5 & 7.1 \\
\hline Total & 70 & 100.0 \\
\hline
\end{tabular}

Table No 7 Pi Chart Shows measurements of actual birth weight. The maximum Actual birth weight was 3.00 which shows similarity with sonographically estimated fetal weight

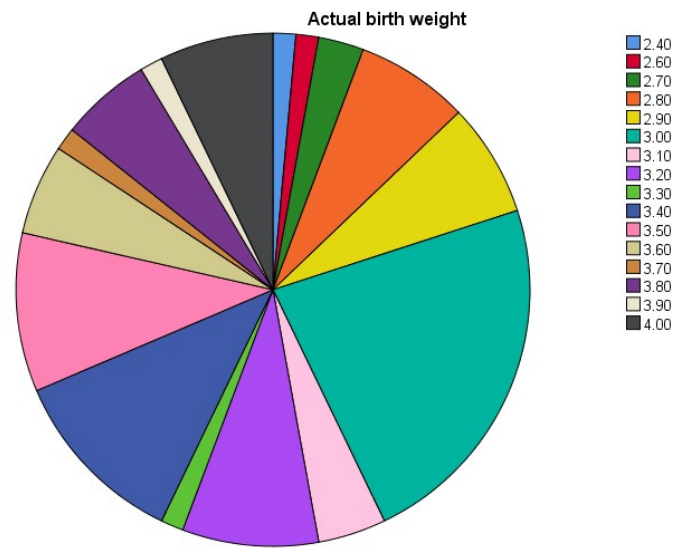

Table No 7: Shows estimated fetal weight by Hadlock formula The maximum values of sonographically estimated fetal weight by Hadlock formula was 3.23 and 3.74 which show similarity with actual birth weight.

\begin{tabular}{|c|c|c|c|}
\hline & & $\begin{array}{l}\text { Frequenc } \\
\mathrm{y}\end{array}$ & Percent \\
\hline \multirow[t]{20}{*}{ Valid } & 2.70 & 1 & 1.4 \\
\hline & 2.80 & 1 & 1.4 \\
\hline & 2.81 & 1 & 1.4 \\
\hline & 2.84 & 1 & 1.4 \\
\hline & 2.89 & 1 & 1.4 \\
\hline & 2.90 & 1 & 1.4 \\
\hline & 2.92 & 1 & 1.4 \\
\hline & 2.94 & 1 & 1.4 \\
\hline & 2.95 & 1 & 1.4 \\
\hline & 2.96 & 2 & 2.9 \\
\hline & 3.00 & 1 & 1.4 \\
\hline & 3.01 & 1 & 1.4 \\
\hline & 3.02 & 1 & 1.4 \\
\hline & 3.03 & 1 & 1.4 \\
\hline & 3.07 & 1 & 1.4 \\
\hline & 3.08 & 1 & 1.4 \\
\hline & 3.09 & 1 & 1.4 \\
\hline & 3.11 & 1 & 1.4 \\
\hline & 3.14 & 2 & 2.9 \\
\hline & 3.17 & 1 & 1.4 \\
\hline
\end{tabular}




\begin{tabular}{|c|c|c|}
\hline 3.20 & 1 & 1.4 \\
\hline 3.21 & 2 & 2.9 \\
\hline 3.23 & 3 & 4.3 \\
\hline 3.25 & 1 & 1.4 \\
\hline 3.29 & 2 & 2.9 \\
\hline 3.31 & 1 & 1.4 \\
\hline 3.32 & 1 & 1.4 \\
\hline 3.35 & 2 & 2.9 \\
\hline 3.37 & 1 & 1.4 \\
\hline 3.38 & 1 & 1.4 \\
\hline 3.39 & 1 & 1.4 \\
\hline 3.41 & 1 & 1.4 \\
\hline 3.42 & 1 & 1.4 \\
\hline 3.43 & 1 & 1.4 \\
\hline 3.45 & 2 & 2.9 \\
\hline 3.47 & 2 & 2.9 \\
\hline 3.49 & 1 & 1.4 \\
\hline 3.50 & 2 & 2.9 \\
\hline 3.51 & 2 & 2.9 \\
\hline 3.53 & 1 & 1.4 \\
\hline 3.57 & 2 & 2.9 \\
\hline 3.58 & 1 & 1.4 \\
\hline 3.59 & 1 & 1.4 \\
\hline 3.60 & 1 & 1.4 \\
\hline 3.68 & 1 & 1.4 \\
\hline 3.69 & 1 & 1.4 \\
\hline 3.72 & 1 & 1.4 \\
\hline 3.74 & 3 & 4.3 \\
\hline 3.75 & 1 & 1.4 \\
\hline 3.76 & 1 & 1.4 \\
\hline 3.88 & 2 & 2.9 \\
\hline 3.89 & 1 & 1.4 \\
\hline 4.01 & 1 & 1.4 \\
\hline 4.19 & 1 & 1.4 \\
\hline 4.24 & 1 & 1.4 \\
\hline Total & 70 & 100.0 \\
\hline
\end{tabular}

Table No 8: Pi chart Shows estimated fetal weight by Hadlock formula. The maximum values of sonographically estimated fetal weight by Hadlock formula was 3.23 and 3.74 which show similarity with actual birth weight. 

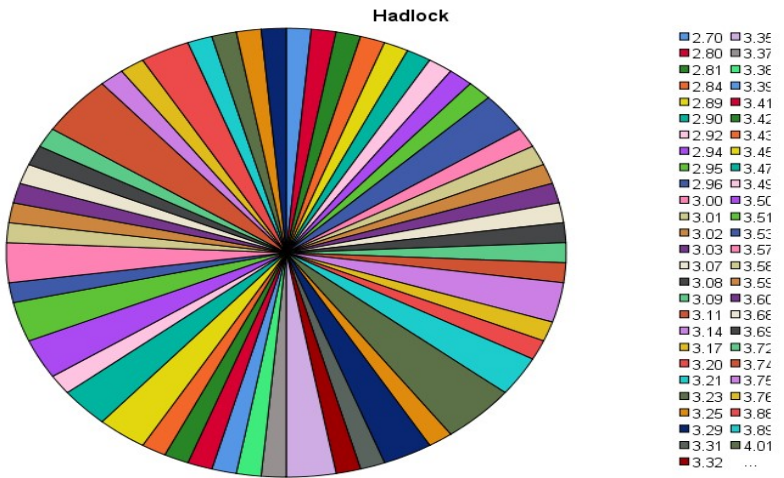

Table No 9 : Shows estimated fetal weight by Shaperad formula The maximum values of sonographically estimated fetal weight by Shaperad formula was 3.21 which show similarity with actual birth weight.

\begin{tabular}{|c|c|c|c|}
\hline & & Frequency & Percent \\
\hline \multirow[t]{29}{*}{ Valid } & 2.73 & 2 & 2.9 \\
\hline & 2.75 & 1 & 1.4 \\
\hline & 2.80 & 1 & 1.4 \\
\hline & 2.83 & 1 & 1.4 \\
\hline & 2.85 & 2 & 2.9 \\
\hline & 2.86 & 1 & 1.4 \\
\hline & 2.90 & 1 & 1.4 \\
\hline & 2.93 & 1 & 1.4 \\
\hline & 2.94 & 2 & 2.9 \\
\hline & 2.99 & 1 & 1.4 \\
\hline & 3.00 & 1 & 1.4 \\
\hline & 3.02 & 1 & 1.4 \\
\hline & 3.03 & 1 & 1.4 \\
\hline & 3.04 & 2 & 2.9 \\
\hline & 3.05 & 1 & 1.4 \\
\hline & 3.06 & 2 & 2.9 \\
\hline & 3.11 & 2 & 2.9 \\
\hline & 3.12 & 2 & 2.9 \\
\hline & 3.16 & 2 & 2.9 \\
\hline & 3.17 & 2 & 2.9 \\
\hline & 3.19 & 1 & 1.4 \\
\hline & 3.21 & 4 & 5.7 \\
\hline & 3.22 & 2 & 2.9 \\
\hline & 3.31 & 1 & 1.4 \\
\hline & 3.35 & 1 & 1.4 \\
\hline & 3.38 & 2 & 2.9 \\
\hline & 3.39 & 2 & 2.9 \\
\hline & 3.41 & 1 & 1.4 \\
\hline & 3.43 & 2 & 2.9 \\
\hline
\end{tabular}




\begin{tabular}{|c|c|c|}
\hline 3.44 & 1 & 1.4 \\
\hline 3.46 & 1 & 1.4 \\
\hline 3.47 & 2 & 2.9 \\
\hline 3.48 & 1 & 1.4 \\
\hline 3.49 & 1 & 1.4 \\
\hline 3.57 & 2 & 2.9 \\
\hline 3.62 & 1 & 1.4 \\
\hline 3.66 & 2 & 2.9 \\
\hline 3.67 & 2 & 2.9 \\
\hline 3.69 & 1 & 1.4 \\
\hline 3.70 & 1 & 1.4 \\
\hline 3.72 & 2 & 2.9 \\
\hline 3.73 & 1 & 1.4 \\
\hline 3.79 & 1 & 1.4 \\
\hline 3.84 & 1 & 1.4 \\
\hline 3.87 & 1 & 1.4 \\
\hline 3.91 & 1 & 1.4 \\
\hline 3.97 & 1 & 1.4 \\
\hline 4.20 & 1 & 1.4 \\
\hline 4.23 & 1 & 1.4 \\
\hline Total & 70 & 100.0 \\
\hline
\end{tabular}

Table No 10: Pi Chart Shows estimated fetal weight by Shaperad formula the maximum values of sonographically estimated fetal weight by Shaperad formula was 3.21 which show similarity with actual birth weight.
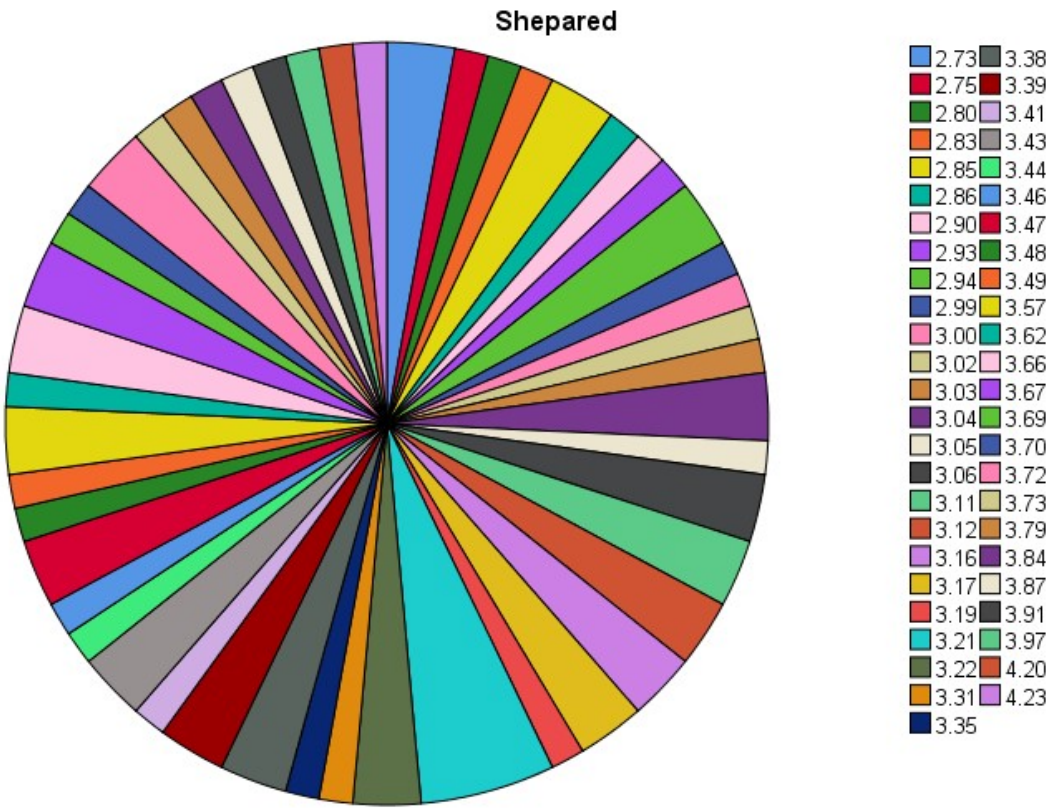

Table No 11: Shows estimated fetal weight by Shinzouka formula The maximum values of sonographically estimated fetal weight by Shinzouka formula was 3.43 which show similarity with actual birth weight. 


\begin{tabular}{|c|c|c|c|}
\hline & & Frequency & Percent \\
\hline Valid & 2.72 & 1 & 1.4 \\
\hline & 2.78 & 1 & 1.4 \\
\hline & 2.82 & 1 & 1.4 \\
\hline & 2.86 & 1 & 1.4 \\
\hline & 2.90 & 1 & 1.4 \\
\hline & 2.91 & 2 & 2.9 \\
\hline & 2.93 & 2 & 2.9 \\
\hline & 2.94 & 1 & 1.4 \\
\hline & 2.96 & 1 & 1.4 \\
\hline & 3.00 & 2 & 2.9 \\
\hline & 3.02 & 1 & 1.4 \\
\hline & 3.03 & 1 & 1.4 \\
\hline & 3.06 & 1 & 1.4 \\
\hline & 3.07 & 1 & 1.4 \\
\hline & 3.10 & 1 & 1.4 \\
\hline & 3.11 & 3 & 4.3 \\
\hline & 3.12 & 1 & 1.4 \\
\hline & 3.15 & 1 & 1.4 \\
\hline & 3.17 & 1 & 1.4 \\
\hline & 3.18 & 2 & 2.9 \\
\hline & 3.21 & 2 & 2.9 \\
\hline & 3.22 & 1 & 1.4 \\
\hline & 3.23 & 2 & 2.9 \\
\hline & 3.24 & 1 & 1.4 \\
\hline & 3.27 & 1 & 1.4 \\
\hline & 3.29 & 1 & 1.4 \\
\hline & 3.31 & 2 & 2.9 \\
\hline & 3.35 & 1 & 1.4 \\
\hline & 3.37 & 2 & 2.9 \\
\hline & 3.39 & 1 & 1.4 \\
\hline & 3.40 & 2 & 2.9 \\
\hline & 3.43 & 4 & 5.7 \\
\hline & 3.44 & 1 & 1.4 \\
\hline & 3.45 & 1 & 1.4 \\
\hline & 3.47 & 2 & 2.9 \\
\hline & 3.50 & 1 & 1.4 \\
\hline & 3.54 & 1 & 1.4 \\
\hline & 3.56 & 1 & 1.4 \\
\hline & 3.59 & 1 & 1.4 \\
\hline
\end{tabular}




\begin{tabular}{|c|c|c|}
\hline 3.62 & 1 & 1.4 \\
\hline 3.64 & 1 & 1.4 \\
\hline 3.68 & 1 & 1.4 \\
\hline 3.69 & 1 & 1.4 \\
\hline 3.70 & 1 & 1.4 \\
\hline 3.71 & 1 & 1.4 \\
\hline 3.72 & 3 & 4.3 \\
\hline 3.73 & 1 & 1.4 \\
\hline 3.75 & 1 & 1.4 \\
\hline 3.80 & 1 & 1.4 \\
\hline 3.87 & 1 & 1.4 \\
\hline 3.88 & 1 & 1.4 \\
\hline 4.06 & 1 & 1.4 \\
\hline 4.11 & 1 & 1.4 \\
\hline Total & 70 & 100.0 \\
\hline
\end{tabular}

Table No 12: Pi Chart Shows estimated fetal weight by Shinzouka formula The maximum values of sonographically estimated fetal weight by Shinzouka formula was 3.43 which show similarity with actual birth weight.
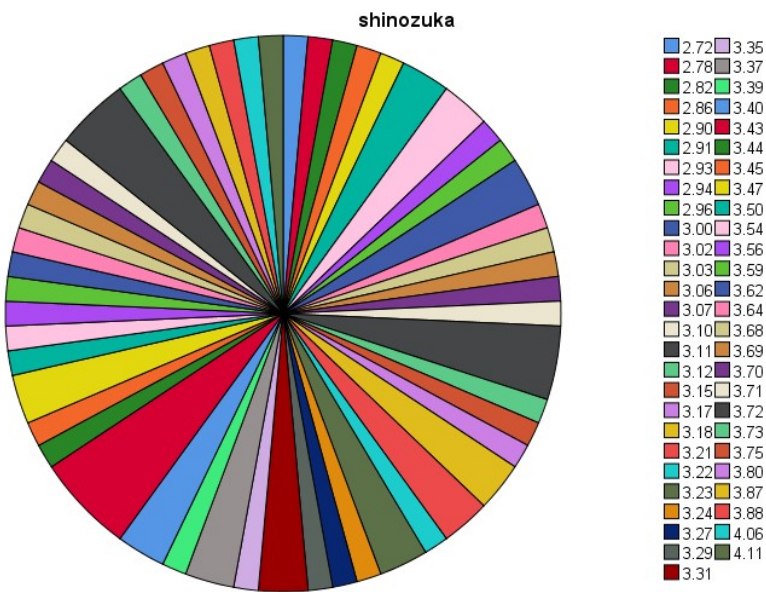

Table No 13: Shows estimated fetal weight by warsof formula the maximum values of sonographically estimated fetal weight by Warsof formula was 2.97 and 3.07 which show similarity with actual birth weight.

\begin{tabular}{ll|l|l|} 
& & Frequency & Percent \\
\hline Valid & 2.59 & 2 & 2.9 \\
\cline { 2 - 4 } 2.61 & 1 & 1.4 \\
\hline 2.66 & 1 & 1.4 \\
\hline 2.69 & 1 & 1.4 \\
\hline 2.71 & 2 & 2.9 \\
\hline 2.72 & 1 & 1.4 \\
\hline 2.77 & 1 & 1.4 \\
\hline 2.79 & 1 & 1.4 \\
\hline 2.80 & 3 & 4.3 \\
\hline
\end{tabular}




\begin{tabular}{|c|c|c|}
\hline 2.86 & 1 & 1.4 \\
\hline 2.87 & 1 & 1.4 \\
\hline 2.89 & 2 & 2.9 \\
\hline 2.90 & 2 & 2.9 \\
\hline 2.92 & 2 & 2.9 \\
\hline 2.97 & 4 & 5.7 \\
\hline 3.01 & 2 & 2.9 \\
\hline 3.02 & 2 & 2.9 \\
\hline 3.04 & 1 & 1.4 \\
\hline 3.06 & 1 & 1.4 \\
\hline 3.07 & 4 & 5.7 \\
\hline 3.10 & 1 & 1.4 \\
\hline 3.16 & 1 & 1.4 \\
\hline 3.20 & 1 & 1.4 \\
\hline 3.22 & 1 & 1.4 \\
\hline 3.23 & 2 & 2.9 \\
\hline 3.24 & 1 & 1.4 \\
\hline 3.26 & 1 & 1.4 \\
\hline 3.27 & 1 & 1.4 \\
\hline 3.29 & 1 & 1.4 \\
\hline 3.31 & 1 & 1.4 \\
\hline 3.32 & 1 & 1.4 \\
\hline 3.33 & 2 & 2.9 \\
\hline 3.35 & 1 & 1.4 \\
\hline 3.37 & 1 & 1.4 \\
\hline 3.40 & 1 & 1.4 \\
\hline 3.41 & 1 & 1.4 \\
\hline 3.45 & 1 & 1.4 \\
\hline 3.49 & 1 & 1.4 \\
\hline 3.50 & 2 & 2.9 \\
\hline 3.51 & 2 & 2.9 \\
\hline 3.54 & 2 & 2.9 \\
\hline 3.56 & 2 & 2.9 \\
\hline 3.62 & 1 & 1.4 \\
\hline 3.68 & 1 & 1.4 \\
\hline 3.70 & 1 & 1.4 \\
\hline 3.74 & 1 & 1.4 \\
\hline 3.82 & 1 & 1.4 \\
\hline 4.03 & 1 & 1.4 \\
\hline 4.08 & 1 & 1.4 \\
\hline
\end{tabular}




$\begin{array}{lll}\text { Total } & 70 & 100.0\end{array}$

Table No 14: Pi Chart Shows estimated fetal weight by warsof formula the maximum values of sonographically estimated fetal weight by Warsof formula was 2.97 and 3.07 which show similarity with actual birth weight.
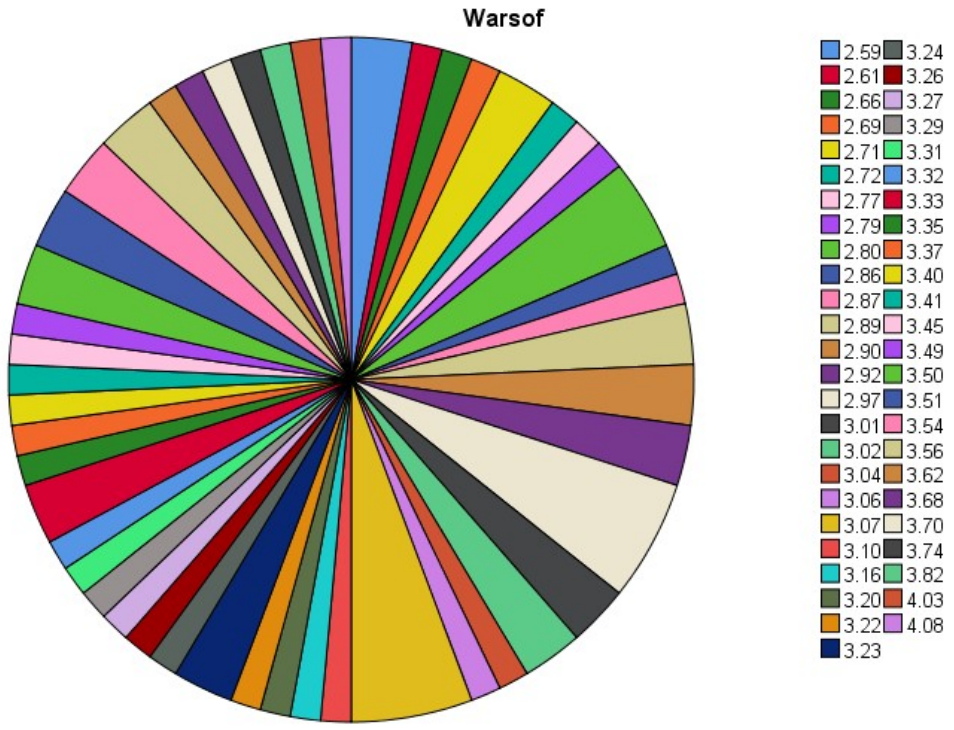

Figure 1: The image shows the diaphysis and cartilaginous epiphysis of the condyles and the major trochanter are both visible on this sonogram of a fetal femur. The femur length (FL) is measured by placing the callipers at the bone-cartilage junction.

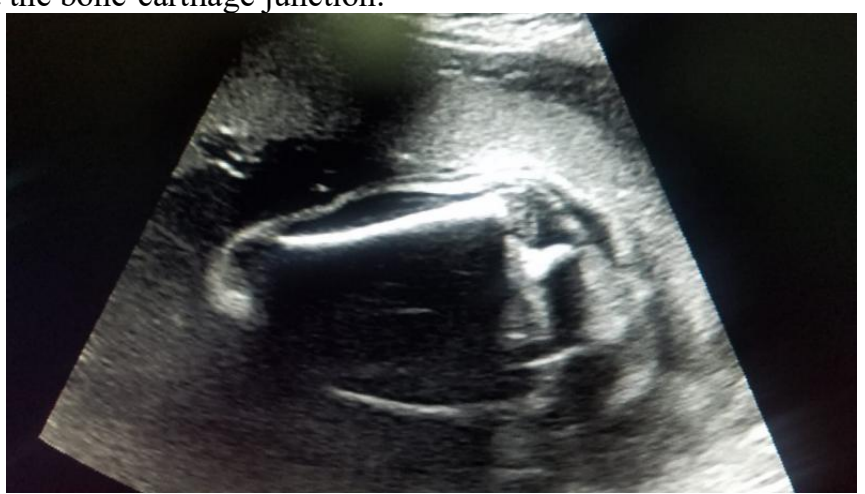

Figure 2: The image shows 27 weeks gestation, the stomach appears as a cystic formation in the left upper quadrant in a transverse plane of the fetal abdomen at the anatomic level of the abdominal girth

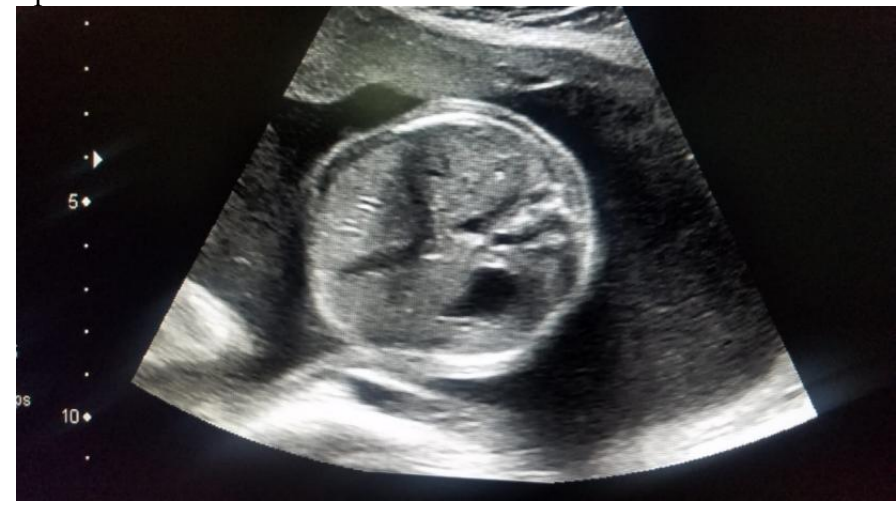

Figure 3: In an axial plane, the HC is taken of fetus. The thalamus (T) and cavum septum pellucidum (CSP are 
seen in the image. Both calvarial (C) margins are equally spaced from the midline. The $\mathrm{HC}$ is calculated by measuring the circumference of the bone.

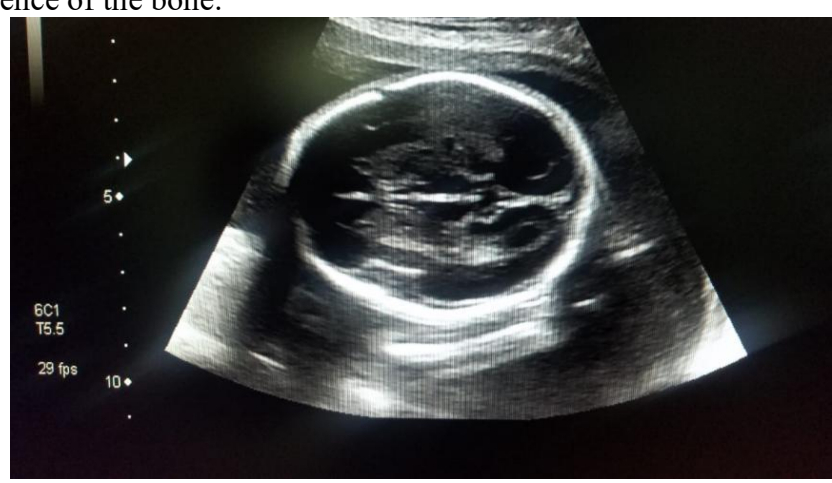

